\title{
Assessment of the Impact of EU Sanctions on Budget Revenues of Russia in the Context of New Industrialization in Terms of National Dimension
}

\author{
Andrey Anisimov*, Oksana Kolotkina, and Inara Yagofarova \\ Ural State University of Economics, 620144 Yekaterinburg, Russia
}

\begin{abstract}
The article examines topical issues that assess the impact of EU sanctions on the volume of tax revenues of the consolidated budget of Russia. The main purpose of this study is an attempt to develop a factor model that allows assessing the sanctions impact on the specified tax revenues, describing and analyzing the factors that directly or indirectly affect the formation of the consolidated budget revenues of the Russian Federation, identifying the corresponding relationships during the period of new industrialization. A separate stage of the presented study is associated with the development of the above model, which evaluates the sanctions effect on the composition of tax revenues of the consolidated budget of the Russian Federation and verification of the adequacy of this model. The authors' own research made it possible to develop a conceptual factor model that assesses the impact of the sanctions effect of the EU countries on the composition and volume of tax revenues of the consolidated budget of the Russian Federation, the use of which makes it possible to analyze the proceeds from the tax payments that have come under the influence of the sanctions. The model presented by the authors makes it possible to fundamentally assess the real impact of the applied sanctions on tax revenues of the consolidated budget of the Russian Federation, to develop appropriate directions in the development of the country during the period of the new industrialization of the Russian state.
\end{abstract}

\section{Introduction}

By new industrialization, the authors understand the interconnected, comprehensive development of the basic (leading) types of branches of modern industry, which should function and develop on the basis of a new domestic scientific and technical background. At any time, especially during the period of new industrialization, the use of any foreign sanctions aims to undermine the scientific, technological and industrial development of Russia, create problems in the field of improvement and development of all leading activities aimed at ensuring a significant improvement in the socio-economic situation in the country, increasing the level and quality of life of citizens of the Russian Federation, on

\footnotetext{
*Corresponding author: 13051957@bk.ru
} 
security, political and economic independence, increasing the role and influence of Russia in the world. This objectively raises the problem of the presence and assessment of the sanctions impact of the EU countries associated with the formation of income from taxes and fees in the budgetary system of the Russian Federation, which is quite relevant [1, p. 137]. The main goal of this study is the formation of a conceptual factor model, the purpose of which is to describe and analyze the factors that affect the processes associated with the formation of tax revenues to the budget, the possibility of their systematization, the definition and analysis of the interconnections of the relevant relationships regarding the conditions of new industrialization. This, in turn, entails the need to solve a set of tasks that are associated, respectively, with the main stages in the receipt of income from taxes and fees, which tend to decrease as a result of the sanctions impact, adjustments to the methodology for their calculation, the need to systematize the main estimated indicators, generalization of the available results. A separate stage of the study observes the need to develop a factor model in a conceptual form that makes it possible to assess the consequences of the sanctions influence on tax payments to the consolidated budget of the Russian Federation, that is, from the perspective of the national dimension.

The imposition of sanctions against the Russian Federation (March 2014) was the response of the EU countries to the well-known Crimean referendum. The result was the adoption of more than fifty different acts in the form of decisions and regulations by the European Union. Note that the sanctions were introduced incrementally: first, relatively mild in the form of a ban on entry and transit, freezing assets in relation to individuals, then rather tough in the form of the introduction of so-called "sectoral sanctions in the banking, defense and energy sectors" [2, p. 1145].

\section{Materials and Methods}

The consequences of the imposition of sanctions falling on the period of the country's new industrialization, and Russia's response to the economies of individual EU states, are sufficiently represented by Russian and foreign researchers. A general description of the EU sanctions impact on Russia have been presented in the works of A. Muranov and A. Belegova [3]; the economic consequences of the EU sanctions pressure on Russia have been studied and the Russian counter-sanctions in response have been presented in the studies of D.V. Kashparova and O.S. Smirnova [4], A.N. Barkovsky A.N., S.S. Alabyan and O.V. Morozenkova [5]. The results of the impact of "sectoral sanctions" on the economy of the Russian Federation can be seen in the works of A.V. Bykova and M.S. Sobol [6], the problem of the formation of the revenue side of the consolidated budget from tax payments is considered in the study by I.N. Platonova and I.P. Gurova [7]. It is also necessary to highlight quite specific foreign publications devoted to the problems of sanctions directed against our country in the banking, energy and defense sectors. The studies in the legislative field on possible solutions to problems (Rovetta D., Beretta L.K.) [8], issues of structuring the Russian economy in the presence of economic sanctions (Aalto P., Forsberg T.) [9], impact of sanctions pressure in the field of agricultural policy in the European Union and the Russian Federation (Kapsdorferova Z., Sviridova O.) [10] have been presented. The effectiveness of sanctions (Gimmelli F.) [11], economic and political sanctions impacts as tools of strategic competition, emerging opportunities and risks in the relevant aspect have been presented as well (Krause J.) [12]. The research is based on the publications presented in the bibliographic description of the scientific research by the domestic and foreign authors.

Studying the problem associated with the formation of the revenue side of the consolidated budget of Russia under the influence of the sanctions effect of the European Union, the authors analyzed the legislation of the Russian Federation in the tax and 
budgetary spheres, detailed individual taxes in order to more adequately distribute them, based on their significance. Based on our own research [13, p.25-26], using the method of economic and mathematical modeling, that is, we used the functions that reflect in mathematical form the dependence of some variables (indicators or factors)) on others, as well as graphs or tables, which reflect the interaction and interdependence of two or more variables, the authors have formed a conceptual factor model for assessing the sanctions impact of the EU countries on the volume of tax revenues to the consolidated budget of the Russian Federation. The application of the presented model made it possible to single out a group of taxes that have a decisive effect on the amount of tax revenues to the consolidated budget, as well as to analyze exactly those tax payments on which EU sanctions have a real effective impact. Thus, the problem of developing an economic and mathematical model that makes it possible to assess the sanctions effect of the EU countries on the volume of tax revenues to the consolidated budget of the Russian Federation seems to be quite relevant.

\section{Results and Discussions}

The problem associated with the formation of the above conceptual factor model can be solved using the method of economic and mathematical modeling, which, in particular, involves a simplified reflection of the existing or possible situation using an appropriate equation or system of equations, a table or set of tables, a graph or a set graphs with which one can describe the relationship and interaction of the key indicators, parameters or factors $[17, \mathrm{p} .62]$. The economic model explains the impact of the economic environment over the economic parameters or factors; with the help of mathematical modeling, it is supposed to use the functions reflecting the relationship and interdependence of some parameters or factors on others, as well as graphs depicting the relationship between two or more parameters or factors $[18, \mathrm{p} .475]$. Thus, tax revenues (composition and volume) to the consolidated budget of the Russian Federation can be presented as a function:

$$
\mathrm{Qt}=\mathrm{f}(\mathrm{X} 1, \mathrm{X} 2, \mathrm{X} 3 \ldots \mathrm{Xn} ; \mathrm{Y} 1, \mathrm{Y} 2, \mathrm{Y} 3 \ldots \mathrm{Yn} ; \mathrm{Z1}, \mathrm{Z2}, \mathrm{Z3} \ldots \mathrm{Zn} ; \mathrm{V1}, \mathrm{V} 2, \mathrm{~V} 3 \ldots \mathrm{Vn} ; \mathrm{H} 1, \mathrm{H} 2 \text {, }
$$

where: Qt - tax revenues of the budgetary system of the Russian Federation;

X1, X2, X3...Xn; Y1, Y2, Y3...Yn; Z1, Z2, Z3...Zn; V1, V2, V3...Vn; H1, H2, $\mathrm{H} 3 \ldots \mathrm{Hn}$ - factors affecting the amount of tax revenues.

In order to form a conceptual factor model for assessing the impact of EU sanctions on tax revenues of the budgetary system of the Russian Federation, it is necessary to solve the following tasks:

1) identification of factors affecting tax revenues to the budget, that is $\mathrm{X} 1, \mathrm{X} 2$, X3...Xn; Y1, Y2, Y3...Yn; Z1, Z2, Z3...Zn; V1, V2, V3...Vn; H1, H2, H3...Hn;

2) detailing the selected factors;

3) determination of the values of each of the selected factors;

4) determination of the influence ("weight") of each of the selected factors;

5) exclusion of factors that have practically no effect on the volume of tax revenues;

6) clarification of the relationships and interactions of the selected factors and their "weight" value, taking into account the discarded factors;

7) transition from general function $\mathrm{Qt}=\mathrm{f}(\mathrm{X} 1, \mathrm{X} 2, \mathrm{X} 3 \ldots \mathrm{Xn}$; Y1, Y2, Y3...Yn; Z1, $\mathrm{Z2}, \mathrm{Z3} \ldots \mathrm{Zn}$; V1, V2, V3..Vn; H1, H2, H3...Hn) to the optimal function Qopt $=\mathrm{f}((\mathrm{X} 1$, X5; Y4, Y6; Z3, Z7; V2, V8; H6, H7).

8) assessment of the influence of the sanctions impact of the EU countries on the composition and volume of tax revenues to the consolidated budget of the Russian Federation. 
The listed tasks and relationships are presented by the authors in Fig. 1 as a conceptual factor model.

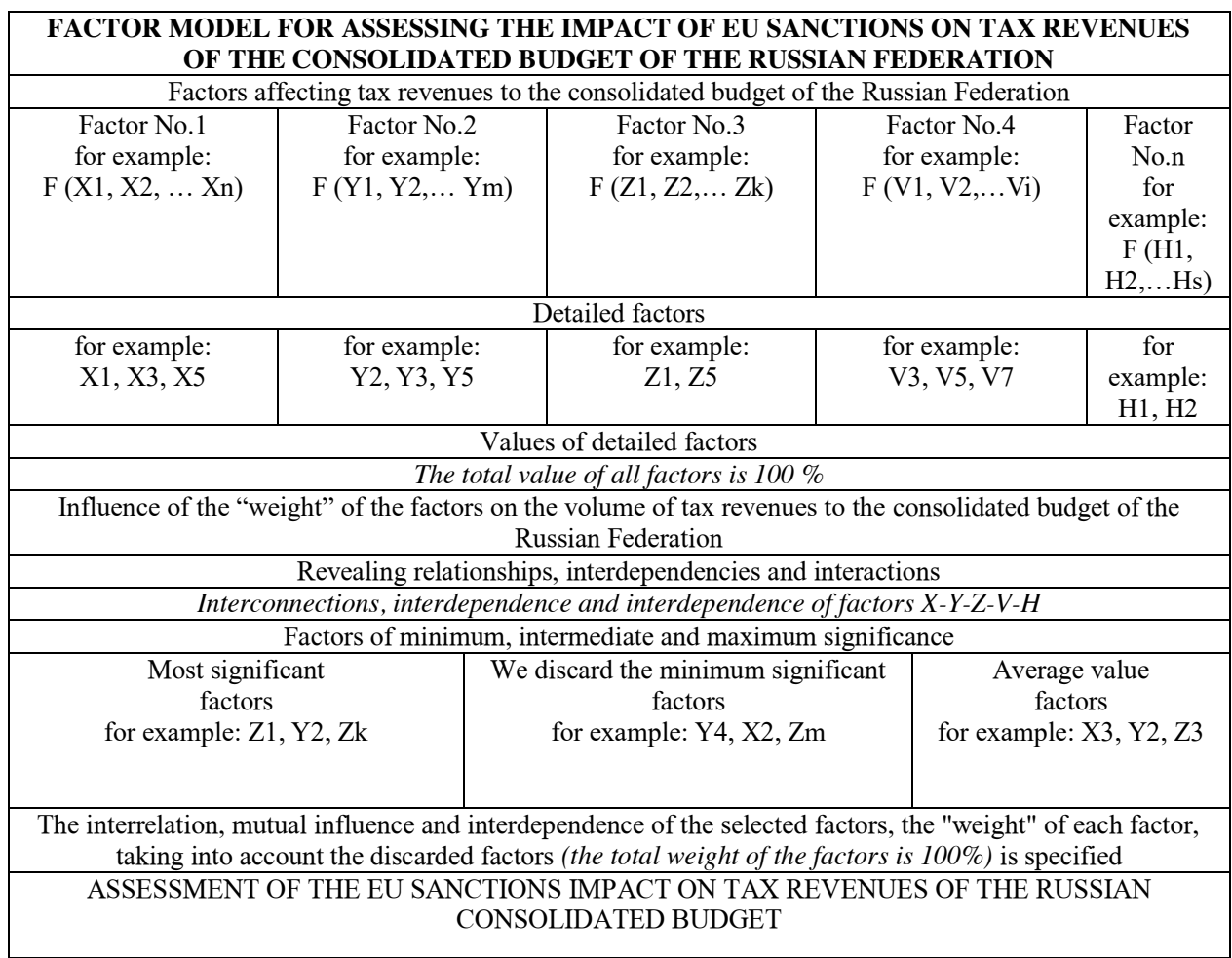

Fig. 1. Conceptual factor model for assessing the impact of EU sanctions on tax revenues of the consolidated budget of Russia

Figure 1 shows that the model makes it possible to assess the EU sanctions impact on the volume of tax revenues of the consolidated budget of the Russian Federation. Note that the lack of consideration of factors that have a "minimum value" entails a decrease in the accuracy of the presented model, but makes it possible to identify those factors that should be given special attention. It is this moment that is especially relevant given limited "economic, informational, organizational, political and other resources" [19, p.47].

The developed model allows us to conclude that the main factors affecting the volume of tax revenues to the consolidated budget are: the number of taxes and their types, the object of the tax, the composition of the tax base, the size of the tax rate, "quality" and the number of taxpayers. The authors believe that the types of the taxes and, especially, corporate income tax, VAT, various types of excise taxes, personal income tax, and mineral extraction tax act as a particularly significant factor. Note that the demonstration of specific indicators is not the subject of the presented work, since the article talks about a conceptual (hereinafter, italics - auth.) model for assessing the sanctions impact of the European Union on consolidated budget revenues from tax payments. We also note that, if necessary, the amount of tax revenues is revealed from the report on the execution of the consolidated budget of the Russian Federation (information is presented on the official website of the Federal Treasury of Russia); in addition, the existing dynamics can be identified and correlated. Carrying out fairly simple calculations related to the calculation of interest or their shares, allows you to evaluate the "weight value" of almost any of the listed taxes in relation to their total part. It is clear that the factor designated by the authors as the size of the tax rate is a constant value (during a fixed time interval); therefore, this factor is 
excluded from the analyzed ones (the authors mean that there is practically no influence on the possible change in tax revenues to the consolidated budget under the influence of sanctions restrictions). Otherwise: the size of tax rates, or the composition of the tax base, although they affect the amount of tax revenues, do not change their value from the presence or absence of sanctions restrictions. Thus, the sanctions restrictions on the amount of tax revenues to the budget have no effect in this situation. However, the authors consider the inclusion of the listed factors in the proposed model as mandatory due to the fact that it is incorporated in the conceptual basis of the model itself - the presence and possibility of taking into account all possible factors, which should not depend on their further "weight". Also, the authors do not rule out the situation that replenishment of actual or planned "tax losses" of the consolidated budget at the level of legislation, it is permissible to change the value of tax rates or the composition of the tax base for certain taxes (as practice shows, usually in terms of increasing or expanding). Here, a "direct connection" between the size of tax rates and sanctions pressure will be obvious (the authors do not exclude that an increase in VAT rate from $18 \%$ to $20 \%$ is a "direct connection" with the imposed sanctions). This kind of reasoning is quite applicable in the analysis of other factors listed in the model.

More or less accurate identification of the degree of influence of sanctions restrictions on the size of the consolidated budget revenues of the Russian Federation, analysis of quantitative (measurable) factors associated with the introduction of sanctions by the EU countries can be identified using a brief analysis of the types and nature of such factors. Analyzing the known sanctions, we can conclude that they are aimed at reducing or even preventing the activities of Russian enterprises and organizations in the most important market segments, both European and global. This is especially true of those markets that account for a large "share of the foreign trade turnover of the Russian Federation" [14]. At the same time, the mechanisms of a political and informational nature are used [15, p. 997], as a result of which foreign enterprises have the opportunity to prospectively increase their share in the European (primarily) market [16, p.49-50]. It should be noted that "personal" sanctions [3] in the form of a ban on entry into the territory of the European Union or passage through this territory of individual citizens of the Russian Federation; prohibition of access of individuals to certain assets; a ban on the provision of tourist services in Crimea and Sevastopol for persons of the European Union and other similar events cannot have a serious impact on tax revenues to the consolidated budget of the Russian Federation. If we talk about the "sectoral sanctions" [3], the effect, according to the authors, is similar, since the EU sanctions pressure for the most part was practically compensated by the policy of import substitution and gave a real opportunity to enter other markets.

It should be noted that from the point of view of the logic of factor analysis and this study, further detailing of foreign trade turnover is assumed only in relation to those areas that have come under the influence of sanctions restrictions. This, according to the authors, entails conducting the separate studies in relation to individual sectors (spheres) of the economy that have come under "sanctions pressure", but the "conceptual focus" of our study does not entail such a detailing.

Note that tax revenues to the consolidated budget of the Russian Federation form about $83-85 \%$ of the total income, which is confirmed by the available statistical data [20, p.369]. Accordingly, an adequate assessment of the sanctions restrictions on the amount of tax revenues of the consolidated budget of the Russian Federation is objectively quite relevant. An analysis of the existing trends does not yet entail an unambiguous understanding of how these sanctions affect the amount of tax revenues of the consolidated budget. So, since 2014, export and import volumes have been decreasing, but there is an increase in the growth of agricultural production; increased retail sales. Unfortunately, there is a difficult situation in the labor market, but there is an increase in the income of the consolidated 
budget (given that income from taxes and fees in the consolidated budget of the Russian Federation is about $83-85 \%$ of all income, that is, it makes sense to talk about an increase in tax revenues).

An important point is understanding (see "detailing factors" - author's note) on what part of tax revenues and on what specific taxes the sanction pressure exerts. In our opinion, sanctions have a minimal effect on the amount of income from taxes on property of individuals, transport and land taxes. With regard to receipts from the most "weighty taxes", the taxes objectively "falling" under the sanctions are listed in Fig. 2. Note that the impact of sanctions restrictions is manifested in the part of the taxable base, depending on the participation of the taxpayer (directly or indirectly) in foreign economic activity (FEA) [21, p.160-161].

\begin{tabular}{|c|}
\hline Corporate income tax (when implementing foreign economic activity) \\
\hline Value added tax (in the implementation of foreign economic activity) \\
\hline Excise taxes (in the implementation of foreign economic activity) \\
\hline Personal income tax (when carrying out foreign economic activity) \\
\hline Mineral extraction tax (in the implementation of foreign economic activity) \\
\hline
\end{tabular}

Fig. 2. The main types of tax revenues of the consolidated budget of Russia that are affected by the EU sanctions

The need to clarify the relationship, interaction and interpenetration in the composition of the selected factors, the determination of the "weight" of each of the factors is necessary to clarify the magnitude of possible and real losses from the introduction of sanctions; determining compensatory actions by changing the composition of the counterparties, searching for ways to enter other sales markets; in order to diversify the production, other possible ways [22]. The presented model makes it possible to analyze and assess real losses or gains [23, p.103] from the application of sanctions restrictions, determine the main directions that concentrate the country's efforts necessary for further economic and social development.

\section{Conclusion}

Scientific, technical and industrial development of the state objectively requires the creation of an effective system of organizing and managing the economy - this is also required by the conditions of "new industrialization". An objective necessity is the creation of a separate state body for mobilizing the resources, implementing program-targeted management and scientific and technological development. The problem of sanctions restrictions in such conditions remains and does not lose its relevance. The need to describe and analyze the factors that affect the process of tax revenues flow to the consolidated budget of the Russian Federation, systematize and identify the interactions and interrelationships of these factors entails the need to solve a whole range of complex problems. These tasks entail the need to describe the main stages in the formation of consolidated budget revenues, to understand the essence of the impact of the EU countries' sanctions, and to have adequate methods of analysis and assessment. It is necessary to clarify the relationships and interactions of these factors, their "weight characteristics", understanding of possible losses and (or) gains from the use of sanctions restrictions, opportunities and ways of their compensation and other possibilities [24, p.30]. The conceptual factor model presented by the authors makes it possible to identify and analyze the main factors affecting the size of tax revenues of the consolidated budget of the Russian Federation. In addition, this model makes it possible to assess the real impact of the sanctions of the EU countries on the size of tax revenues of the consolidated budget of the 
country, to determine the directions of activities of public authorities for the further economic and social development of the Russian state [14, p.134].

\section{References}

1. O. Yu. Sergeeva, A. A. Karimov, Economics and Management Issues, 2, 134 (2017)

2. Elena Sysoeva, Elena Budilova, Igor Risin, 27th International Business Information Management Association Conference, 1145 (2016)

3. A. Muranov, A. Belegova, General overview of sanctions imposed by the EU and the US against the Russian Federation, http://sanctionsregulations.ru/

4. D.V. Kashparov, O.S. Smirnova, Economics and Management Issues, 5-1(7), 97 (2016)

5. A. N. Barkovsky, S. S. Alabyan, O. V. Morozenkova, Russian foreign economic Bulletin, 9, 3 (2015)

6. A.V. Bykova, M.S. Sobol, Innovative economy: materials of the IV international scientific conference, 39 (2017)

7. I. N. Platonova, I. P. Gurova, Russian foreign economic Bulletin, 5, 49 (2015)

8. Davide Rovetta, Laura Carola Beretta, Global trade and customs journal, 12(6), 240 (2017)

9. Pami Aalto, Tuomas Forsberg, Asia europe journal, 14(2), 221 (2016)

10. Zuzana Kapsdorferova, Olga Sviridova, International Scientific Days (ISD) Conference on Agri Food Value Chain - Challenges for Natural Resources Management Society, 43 (2016)

11. Francesco Giumelli, International Conference on Coercive Diplomacy, Sanctions and International Law, 246 (2016)

12. Joachim Krause, International Conference on Coercive Diplomacy, Sanctions and International Law, 270 (2016)

13. A. L. Anisimov, S.V. Shirpuzhev, Manager, 3(67), 25 (2017)

14. Economic sanctions against Russia: reasons, analysis, lists, consequences, http://weic.info/ekonomicheskie_stati/

15. Elin Hellquist, Cambridge review of international affairs, 29(3), 997 (2016)

16. Veniamin Simonov, Voprosy ekonomiki, 2, 49 (2015)

17. Yu.B. Melnikov, Kazan pedagogical journal, 1(114), 62 (2016)

18. N.V. Ryskal, Young scientist, 22, 475 (2015)

19. N.G. Duplenko, N.V. Sharoshina, E.A. Nosachevskaya, T. Vezheyski, G. Shchubelek, M. Kedzer-Laskovska, M. Semyonek, A. Kuyava, Cross-border cooperation in European integration processes, 247 (2011)

20. Russia in numbers. Short. stat. bull., 511 (2017)

21. N.G. Duplenko, Bulletin of the Baltic Federal University named after I. Kant. Series: Humanities and social Sciences, 9, 160 (2013)

22. E.V. Rodionova, Modern scientific research and innovation, 11 (2017)

23. Hella Engerer, OSTEUROPA, 65(11-12), 103 (2011)

24. N.F. Ogneva, N.G. Duplenko, Young scientist, 19-1, 30 (2014) 